\title{
LITERATURA ORAL, LENDAS DIAMANTINENSES E FORMAÇÃO LEITORA
}

\section{Oral literature, diamond legend and reader training}

\begin{abstract}
Daniela Luciana Braga Santiago Teixeira - Universidade Federal dos Vales do Jequitinhonha e
\end{abstract} Mucuri/Brasil

RESUMO: Este artigo apresenta os resultados de uma pesquisa cujo propósito foi elaborar um material de apoio para o professor de Língua Portuguesa nos anos finais do ensino fundamental. Esse material visa analisar os elementos presentes em uma das narrativas lendárias da cidade de Diamantina-MG, além de sugerir atividades que visam ao incentivo e à leitura de diversos gêneros literários com o intuito de proporcionar uma melhor compreensão e interpretação do texto no contexto escolar. Elaborou-se um estudo da seguinte lenda: O Tesouro do Padre Brazão (1972). A lenda selecionada é a mais conhecida e possui registro escrito, publicada em meados do século XIX e início do século $\mathrm{XX}$. A pesquisa caracteriza-se como bibliográfica, com abordagem qualitativa, pois busca explicar o conceito de literatura oral, apresentar e analisar a lenda citada. A prática de leitura defendida neste trabalho, muito embora os textos trabalhados tenham origem na tradição oral, parte da premissa de que a literatura é relevante na vida do homem, em função de seu caráter humanizador e por seu potencial de construir não só leitores, mas sujeitos capazes de entender o mundo e a si mesmos. Espera-se que o trabalho com esse material possa, por intermédio do trabalho do professor, apresentar ao potencial aluno a literatura como um objeto de fruição, mediante uma imersão literária que permita a ele admirar, sensibilizar-se e explorar ao máximo as sensações propiciadas pelo texto, levando-o a se identificar com os personagens, culturas, épocas, lugares e costumes diferentes, possibilitando que se depare com outras realidades, bem como que tenha uma visão mais ampla e crítica sobre o mundo e a sociedade.

Palavras-chave: Leitura. Lendas diamantinenses. Literatura.

ABSTRACT: This article presents the results of a research whose proposal was to develop support material for the Portuguese language teacher in the final years of elementary school. This material aims to analyze the elements presented in one of the legendary narratives of the city of Diamantina-MG, in addition to suggesting activities that aim to encourage and levitate several literary genres in order to use and compare better.A study of the following legend was elaborated: The Treasure of padre Brazão (1972). The selected legend is the best know and has a written record, published in the published mid-nineteenth and early twentieth centuries. The research is characterized as bibliographic, as it seeks to explain the concept of oral literature, present and analyze the legend cited. The reading practice defended in this work, although the legends originate from the oral tradition, starts from the premise that literature is fundamental in the life of man, emphasizing its humanizing character for its potential to build not only readers, but subjects capable of understanding the world and themselves. It is expected that the work with this material can, through the work of the teacher, present the potential student as an object of enjoyment, through a literary immersion that allows the student to admire, sensitize and explore the sensations provided by the text to the fullest. Leading the readers

Educação, Psicologia e Interfaces, Volume 4, Número 3, p.1-16, Julho/Setembro, 2020.

ISSN: 2594-5343. DOI: 10.37444/issn-2594-5343.v4i3.250 
to identify with different characters, cultures, eras, places and customs, enabling them to come across with other realities as well as have a broader view of the world and society.

Keywords: Reading. Diamantinese legends. Oral literature.

\section{INTRODUÇÃ̃O}

Para um possível desenvolvimento do leitor literário, é necessário que a escola proporcione ao aluno o contato com diversos tipos de textos literários e que apresentem formas diferentes de cultura e maneiras de pensar o mundo. Elegemos as lendas diamantinenses, que são manifestações artísticas literárias orais. São narrativas das quais podemos depreender a expressão cultural diamantinense e que, por resgatarem a cultura local dos séculos passados, podem propiciar uma prática de leitura capaz de engajar os alunos, portanto motivadora para a formação da competência leitora.

O objetivo geral é investigar as lendas diamantinenses com o propósito de propor atividades com intuito de possibilitar o desenvolvimento do leitor literário por meio da literatura oral. Os objetivos específicos incluem: a) proceder a um levantamento bibliográfico sobre literatura e lendas diamantinenses; b) refletir sobre propostas de ensino de Literatura Oral com base nos documentos oficiais brasileiros de referência e nos textos científicos e/ou pedagógicos sobre a questão. d) sugerir um material de apoio que propõe uma análise dessas narrativas lendárias com base na proposta de Candida Villares Gancho para os anos finais do ensino fundamental com atividades que orientem o desenvolvimento do leitor literário por meio das lendas diamantinenses.

e) contribuir para o fomento da leitura das lendas diamantinenses nas escolas de Diamantina-MG.

\section{MATERIAL E MÉTODO}

Esta seção tem como finalidade apresentar o percurso metodológico da presente pesquisa. Do ponto de vista dos procedimentos técnicos, foi utilizada a pesquisa bibliográfica, que se fundamenta em fontes teóricas como livros, blogs e artigos científicos para sistematizar o tema pesquisado (GIL, 1991, p. 44). Foi utilizado material bibliográfico que abordasse temas como: letramento literário, leitura literária, literatura, ensino da literatura, literatura oral, lendas diamantinenses, entre outros.

Educação, Psicologia e Interfaces, Volume 4, Número 3, p.1-16, Julho/Setembro, 2020.

ISSN: 2594-5343. DOI: 10.37444/issn-2594-5343.v4i3.250 
Quanto aos procedimentos técnicos adotados para a coleta dos dados, trata-se de uma análise documental, pois foram utilizados materiais de fontes como jornais. Convém lembrar que, de acordo com Gil (1991, p. 46), nem sempre é possível fazer uma distinção entre os dois tipos de pesquisa, já que ambos se utilizam de documentos impressos para fins de leitura.

Os documentos consultados nesta pesquisa foram os jornais publicados entre os séculos XVIII e XIX: A Estrella Polar (1941) e A Idéa Nova (1908), que traziam seções dedicadas às lendas diamantinenses. Também foram analisadas as diretrizes curriculares presentes nos documentos oficiais, como CBC (Conteúdos Básicos Comuns de Língua Portuguesa dos Anos Finais do Ensino Fundamental) e PCN (Parâmetros Curriculares Nacionais de Língua Portuguesa do Ensino Fundamental), pois a pesquisa tem um foco pedagógico e direcionado para a produção de material didático para a educação escolar. Assim, fez-se necessário verificar quais as orientações legalmente instituídas no que diz respeito à importância de se trabalhar em sala de aula a diversidade cultural, inclusive a tradição oral, e à importância da formação crítica do aluno no meio que ele está inserido.

Quanto à abordagem de análise dos dados, a pesquisa é qualitativa. Abordar um problema qualitativamente possibilita a leitura da realidade, pois, segundo Chizzotti (2000, p. 79), estabelece-se uma "relação dinâmica entre o mundo real e o sujeito". O conhecimento se constitui também pelo olhar do sujeito que observa, atribuindo significados aos fenômenos e dados coletados.

Em relação aos objetivos, a pesquisa é de caráter exploratório, pois, além de ser flexível, está atrelada à pesquisa bibliográfica, e toda pesquisa bibliográfica é, por natureza, exploratória. No caso deste trabalho, o caráter exploratório permitiu investigar as lendas diamantinenses.

\section{MATERIAL DE APOIO PARA O PROFESSOR: ANÁLISES E SUGESTÕES DE ATIVIDADES DA LENDA DIAMANTINENSE}

\section{O Tesouro do Padre Brazão}

A narrativa do tesouro do Padre Brazão foi publicada no jornal Estrella Polar, no ano de 1972, de forma sintetizada. Posteriormente, vários autores publicaram a lenda, assim como no livro Dias e Noites em Diamantina, do ano 1972, escrito por Aires da

Educação, Psicologia e Interfaces, Volume 4, Número 3, p.1-16, Julho/Setembro, 2020.

ISSN: 2594-5343. DOI: 10.37444/issn-2594-5343.v4i3.250 
Mata Machado Filho. Ao iniciar um dos capítulos do seu livro denominado a Poesia das Lendas, o autor retoma:

Conta à tradição antiga, segundo publicação na Estrela Polar de 23/01/1972: 'Sepultei ao pé de uma jabuticabeira o que não me pertence: duas garrafas de ouro e três chifres de diamantes'. Estas palavras estavam escritas num pedaço de papel encontrado entre os objetos do Padre Brazão, sacerdote que viveu em Diamantina no século XVIII (MACHADO FILHO, 1972, p. 35).

Neste tópico, buscamos a versão da referida lenda, publicada de maneira completa no livro de Soter Couto, titulado Vultos e Fatos em Diamantina. Abordaremos, em seguida, os elementos da narrativa que compõem a lenda do Tesouro do padre Brazão, a saber: o enredo constituído por exposição, complicação, clímax e desfecho; logo em seguida, trataremos dos personagens, narrador, tempo, espaço e ambiente.

A exposição desta narrativa se baseia na confissão de um escravo perante seu leito de morte para um padre chamado Brazão. Percebemos, assim, que a história narrada tratará do roubo de um tesouro. Contudo, a exposição não se dá logo a princípio, já que o escravo, no decorrer do texto, depois de usar uma linguagem rica de metáforas, descritiva e até mesmo poética, confessa um roubo, demonstra arrependimento e suplica o perdão de Deus por intermédio do padre. O escravo confessa ao padre onde está escondido o baú repleto de ouros e diamantes e pede que entregue a quem seja de direito a fortuna:

- Ó Padre, suplico o perdão de Deus.

- Pois não filho. [...]

- Roubei padre - disse o escravo - roubei para tornar a ser livre como dantes e com o dinheiro partir estas algemas que me acorrentaram na África, separando-me para sempre dos meus. [...] Apoderei-me do ouro e diamantes, mercadorias que escravizam os homens, não para me proporcionarem fausto e ostentação, mas para dá-lo em troca de minha liberdade, também roubada. Com um roubo, pagaria outro e só com ele conquistaria de novo, o direito de ser livre (COUTO, 1954, p. 88).

Como a exposição é descrita ao longo do texto, o professor pode usar estratégias que possibilitarão ao aluno adentrar na lenda. Um exemplo seria ler o texto pausado, apresentando em slides até a parte em que o escravo confessa o seu pecado. O professor poderá fazer pausas intercaladas nos parágrafos, indagando respostas dos alunos para especulem sobre o erro do escravo.

Educação, Psicologia e Interfaces, Volume 4, Número 3, p.1-16, Julho/Setembro, 2020.

ISSN: 2594-5343. DOI: 10.37444/issn-2594-5343.v4i3.250 
A complicação na lenda analisada está no momento em que o escravo confessa que ele roubou do Felisberto Caldeira Brant e o contratador foi preso injustamente. $\mathrm{O}$ padre fica cabisbaixo perante a confissão e vem à tona o dia de tal acontecimento que Felisberto é levado preso. Aqui o narrador onisciente é também observador:

Uma forte dispnéia obrigou o escravo a uma pequena pausa. $\mathrm{O}$ sacerdote, cabisbaixo, meditando, recordou-se de que por um modo misterioso e que jamais teve explicação, foi roubado o cofre da Intendência, onde se guardava o produto das lavras do Contratador e onde fazia em depósito grande quantidade de diamantes e ouro pertencentes a Felisberto. Jamais se pode conseguir saber quais foram os autores da ousada empresa. Por mais extensas e minuciosas que fossem as investigações e pesquisas então feitas por ordem do Intendente, nada colheu a devassa que pudesse esclarecer o obscuro caso (COUTO, 1954, p. 90).

O clímax é o momento em que todos aguardam a revelação de onde está o tesouro, que acontece no momento em que o escravo conta para o padre o local exato onde está escondido o tesouro e, logo em seguida, morre:

Minha hora chegou. Morro escravo dos homens e da saudade. A fortuna, Padre Brazão, está na Amontólia, sepultada na distância média que os pés das duas primeiras jabuticabeiras plantadas para o nascente. É sua. Devolva-a a quem é de direito. E silenciou o escravo. Deu-lhe o perdão, retirou-se o sacerdote com o plano concebido de rebuscar o tesouro e entregá-lo a Felisberto, logo que este voltasse do Reino. Voltando ao quarto os assistentes, mal o padre se retirara, ouviram frases desconexas pronunciadas pelo escravo, no delírio do tifo que o consumia. Puxando as cobertas como quem cava a terra com as mãos exclamava: 'Aqui duas botelhas de ouro e três chifres de diamantes, entreguei tudo ao padre Brazão. Não sou criminoso, não os levo'. E a voz foi-se apagando lentamente, numa afirmativa de renúncia de vida (COUTO, 1954, p. 91).

Aqui percebemos a presença de assistentes que ouvem as últimas frases do escravo, falando em frases desconexas do tesouro entregue ao padre Brazão.

O desfecho acontece no momento que o escravo morre e, então, o padre sai em busca do lugar onde está o tesouro escondido, transportando-o para o seu sítio:

Alguns dias depois, numa noite chuvosa e fria, embuçado numa grande capa, foi o Padre Brazão em busca do tesouro. Retirou-o, levou-o, com a luz de uma lanterna, para o seu sítio, algumas centenas de metros dali, no morro que descamba para o córrego Pururuca. A falta de cofres e a

Educação, Psicologia e Interfaces, Volume 4, Número 3, p.1-16, Julho/Setembro, 2020.

ISSN: 2594-5343. DOI: 10.37444/issn-2594-5343.v4i3.250 
perseguição dos Intendentes exigia de todos os habitantes esconderijos difíceis para seus haveres, e parece tê-lo escolhido junto de uma das muitas jabuticabeiras existentes na chácara (COUTO, 1954, p. 91).

Logo em seguida, o referido padre morre: "Morrendo o padre, repentinamente, de uma trombose cerebral, encontraram, rebuscando seus papéis, esta pequena nota: 'Sepultei ao pé de uma delas o que não me pertence: duas garrafas de ouro e três chifres de diamantes'. Esse é o roteiro da tradição”. (COUTO, 1954, p. 91-92).

Como o padre não falou onde estava escondido o ouro, "o ouro ainda estaria lá, pois ninguém conseguiu achá-lo, já que o sacerdote guardou o segredo. O local é, hoje ainda, conhecido com o nome de Brazão, e lá existem várias galerias, restos de uma antiga mineração" (MACHADO FILHO, 1972, p. 35).

Entretanto, a lenda não termina aqui, pois surgem muitas histórias orais em relação ao tesouro que foi escondido pelo padre Brazão. Perdura ainda na voz do povo diamantinense a lenda que ficou na conjunção do delírio do escravo e da linha escrita do sacerdote. Muitos ali, já deixaram o juízo e outros, tempo e energia, à cata do "Tesouro do Padre Brazão".

Um dos que tentaram, já talvez no limiar da loucura, afirmava que, numa hora crepuscular, quando só naquele ermo, ouviu uma voz que o encaminhava para o Sítio onde jaz soterrada a fortuna. A curiosidade fê-lo voltar à procura de quem lhe dava ordem e só percebeu um desmoronar de ossos, levantando uma nuvem branca de pó, que o asfixiou e o atordoou. Foi internado dias depois no manicômio de Barbacena, lá morrendo entre as grades. Muitos já vieram de longínquas paragens, trazidos pela cobiça, e ali sepultaram dinheiro, cavando sem cessar, mas o tesouro continua dormindo no seu esconderijo (COUTO, 1954, p. 92).

Ouve-se falar que perdura até os tempos atuais a aparição de uma luz que acende quando fitamos o nosso olhar no bairro Brazão e acredita-se que essa luz mostra o local que o tesouro do padre está escondido. No entanto, perante os fatos narrados acima, muitos não têm coragem de ir buscar o tesouro escondido. A partir disso, o professor pode sugerir aos alunos que pesquisem por meio de entrevistas com moradores do Bairro Brazão, historiadores e guias turísticos, sobre as histórias que relatam a luz do padre Brazão. Em momento posterior, as informações recolhidas poderão ser discutidas em sala de aula.

A verossimilhança, também presente no enredo, se faz presente nas narrativas

Educação, Psicologia e Interfaces, Volume 4, Número 3, p.1-16, Julho/Setembro, 2020.

ISSN: 2594-5343. DOI: 10.37444/issn-2594-5343.v4i3.250 
ficcionais e é a lógica possível dentro do mundo do texto. Na referida lenda, constatamos a existência real e histórica do Contratador Felisberto em documentos que comprovam os fatos ocorridos em relação ao que é falado dele nos diálogos do escravo e no pensamento do padre. O que é comprovado na história real é que, de fato, o contratador Felisberto fora um homem bom para os garimpeiros e para o Arraial do Tejuco, e que fora preso acusado de roubar a coroa portuguesa.

A lenda, portanto, até onde é possível averiguar, se constrói baseada nesse episódio. Se realmente existiu o escravo que roubou ou não o tesouro, não há como afirmar; mas, dentro da realidade das pessoas que construíram a lenda, o negro realmente existiu assim como o padre Brazão. Se realmente o tesouro está escondido ou não, é impossível alegar com certeza. Mas, dentro das histórias narradas, realmente, ele está escondido no sítio Brazão. O importante, todavia, é que não importa se existiu ou não, porque, se é literatura, não precisa ser verdade. Dentro da realidade fictícia da lenda, todos os fatos e personagens existiram e ainda existem; tanto é que a lenda ainda perdura no imaginário popular até a contemporaneidade.

Nesta lenda, há apenas três personagens: o padre Brazão, que se classifica como personagem principal, uma vez que o Negro confessa para ele que é o responsável por esconder o tesouro após a morte do escravo, configurando-o assim o responsável pela existência da lenda.

Temos o Intendente Felisberto Caldeira Brant, personagem secundário, e, por último, o personagem intitulado Negro por não possuir nomeação, que pertence, quanto à caracterização, à esfera do personagem plano tipo, visto ser apenas reconhecido pela caracterização de sua cor e passado: "um negro que tivera sua liberdade roubada na África e fora trazido ao Brasil em um navio negreiro e vendido por um punhado de moedas". (COUTO, 1954, p.90).

Ainda, o Negro, ou escravo, é o único personagem da lenda que não tem nome, indicando uma representação social da exclusão de pessoas negras e do apagamento de suas identidades. Neste ponto, sobretudo, é importante o professor explorar o preconceito vigente na época em relação ao negro, assim como a exclusão do nome do escravo no texto. É relevante, também, explorar a linguagem poética, as figuras de linguagem presentes na fala do escravo perante sua dor.

Identificamos o narrador como onisciente e também observador, pois, além de

Educação, Psicologia e Interfaces, Volume 4, Número 3, p.1-16, Julho/Setembro, 2020.

ISSN: 2594-5343. DOI: 10.37444 /issn-2594-5343.v4i3.250 
saber sobre a história, é o responsável direto pela narração, adentrando o pensamento do padre:

O sacerdote, cabisbaixo, meditando, recordou-se de que por um modo misterioso e que jamais teve explicação, foi roubado o cofre da Intendência, onde se guardava o produto das lavras do Contratador e onde fazia em depósito grande quantidade de diamantes e ouro pertencentes a Felisberto (COUTO, 1954, p. 90).

Ressalta-se, também, que apesar de na cidade de Diamantina/MG haver uma homenagem por meio da nomeação de um bairro denominado Brazão, não encontramos outro tipo de registro da existência do padre. O único personagem cuja existência possui registro real é o do personagem Intendente Felisberto Caldeira Brant, mencionado tanto pelo Padre Brazão, como pelo Negro.

Identificamos o tempo como cronológico, linear, visto que a narrativa começa da confissão do negro até sua morte.

O escravo cita o nome do seu patrão, o Contratador Felisberto Caldeira Brant, dando-nos pistas, mas, sem uma precisão correta a respeito da época, ou seja, o tempo, quando aconteceram os fatos da narrativa. Felisberto Caldeira Brant foi contratador de Diamantina por volta dos anos de 1749 a 1752. No livro Memórias do Distrito Diamantina, o autor Joaquim Felício dos Santos narra sobre a época do contrabando de diamantes pelos garimpeiros, ou seja, o comércio ilegal de pedras preciosas. Toda a riqueza encontrada teria que ser guardada nos cofres da Intendência e, assim, entregue a Portugal.

Dessa forma, caso fosse o garimpeiro acusado de roubo, além de ser castigado, seria entregue uma parte que foi roubada ao contratador. Felisberto, diferente dos outros contratadores, fazia vistas grossas ao contrabando e não perseguia os garimpeiros, pois, não tinha interesse em tirar vantagem dessas situações: "Felisberto Caldeira não perseguia os garimpeiros, como seus antecessores, e parecia tolerar o contrabando, conquanto da sua punição destes crimes lhe pudesse resultar grande proveito com o confisco dos bens dos condenados" (SANTOS, 1976, p. 115).

Outros estudiosos também descrevem Felisberto Caldeira Brant com traços que acentuam sua figura histórica: "O seu contrato, graças a muitos fatores, inclusive o contrabando que se fazia à larga, correspondeu a uma época de grande prosperidade para o Tejuco, cuja população cresceu depressa e fortunas se fizeram rapidamente, nascendo

Educação, Psicologia e Interfaces, Volume 4, Número 3, p.1-16, Julho/Setembro, 2020.

ISSN: 2594-5343. DOI: 10.37444/issn-2594-5343.v4i3.250 
o luxo e o bom gosto" (TORRES, 1980, p. 300).

No entanto, o referido contratador é denunciado para o Marquês de Pombal, quando alegou que vendia diamantes grandes para particulares e entregava para a Coroa os diamantes menores. Diante de várias provas do envolvimento do contratador em contrabando e também pela acusação do roubo do cofre da Intendência dos diamantes, foi levado preso para Portugal, tendo a confiscação dos seus bens e terminando seus dias em agonia e sofrimento (SANTOS, 1976, p. 120).

Retomando a lenda, o escravo relata o episódio que o contratador foi levado preso, acusado de um roubo que não cometeu:

\begin{abstract}
Não pude hesitar mais. Furtei os diamantes e acumulei a fortuna que ora lhe devolvo. E assim padre, o Intendente Felisberto Caldeira Brant, a quem fui mandado servir como criado, homem fácil e bom, com a fortuna de diamantes que lhe chegava às mãos, de seus diversos serviços de mineração, descuidava muito, deixando sobre as mesas grandes partidas e quase sempre abertas as arcas em que guardava. Apanhando hoje um aqui, amanhã outro ali, acumulei a importância para meu resgate. Pouco me valeu, porque Deus vai libertar-me deste mundo, e para Felisberto foi a condenação (COUTO, 1954, p. 90).
\end{abstract}

Nos estudos de Aires da Mata Machado Filho, Noites e Dias em Diamantina, em seu capítulo sobre a poesia das lendas, ele fala de maneira mais clara em relação ao roubo do cofre da Intendência que o escravo furtou: "O escravo chegou mesmo a furtar o cofre da Intendência, onde se guardava o produto das lavras do Contrato" (MACHADO FILHO, 1972, p. 35). Assim, percebemos que a lenda possui embasamento em fatos verídicos.

O espaço físico onde desenrola a trama se refere ao que, atualmente, é a cidade de Diamantina, situada no estado de Minas Gerais. Isso, porque em algumas frases, constatamos o espaço da narrativa como menção ao córrego Pururuca, onde hoje se encontra o Bairro da Palha; e, no final, cita-se que a lenda "perdura ainda na voz do povo de Diamantina" (COUTO, 1954, p. 92).

O autor Aires da Mata Machado Filho, cita o local onde o padre enterrou o tesouro: "Quando ele morreu, o Padre foi ao local em que estava enterrado o tesouro e o transportou para junto do córrego Pururuca, atrás do Quartel do 3. ${ }^{\circ} \mathrm{BP}$. O ouro ainda estaria lá, pois ninguém conseguiu achá-lo, já que o sacerdote guardou o segredo" (MACHADO FILHO, 1972, p. 35).

Educação, Psicologia e Interfaces, Volume 4, Número 3, p.1-16, Julho/Setembro, 2020.

ISSN: 2594-5343. DOI: $10.37444 /$ issn-2594-5343.v4i3.250 
Logo, a função do espaço na narrativa é o lugar físico onde os personagens se encontram e as ações acontecem, assim, é importante para o aluno compreender que este espaço ainda existe em Diamantina, criando uma proximidade do aluno com a lenda e também cultivando um sentimento de pertencimento, uma vez que o mesmo passará conhecer melhor a história - ainda que fictícia - do local onde vive.

Percebemos por meio das falas do escravo, que se trata de um ambiente que aborda o preconceito racial em relação ao negro, sendo uma atitude característica de uma sociedade escravocrata e racista. Retomamos também que o Negro é o único personagem que não tem nome, é excluído, como se não fosse ser humano, sem existência, sem identidade. Este fato, portanto, caracteriza um ambiente repleto de preconceito, em que se compara o escravo a um animal. Por meio desta observação, nota-se que é de fundamental importância que o professor discuta com os alunos que, depois de séculos, o racismo ainda persiste nos tempos atuais. É necessário que os alunos possam discutir acerca do racismo e o preconceito, e a lenda pode se tornar instrumento dessa reflexão ao reproduzir, em diversos trechos - como quando o negro fala sobre a saudade da África, terra da qual foi roubado - a realidade de uma sociedade que escravizou brutalmente as pessoas negras e tiraram o direito de ter, até mesmo, uma identidade.

O racismo pode ser compreendido como o preconceito de caráter étnico ou racial, baseado em uma visão pré-estabelecida sobre a cultura ou a raça de certa população. Configura-se como um conceito ou imagem determinada sobre uma pessoa ou alguma coisa, o qual pode ser identificado por meio de atos discriminatórios pelas crenças, religiosidade, tipos de cultura, manifestações culturais ou por meio de atitudes desagradáveis, podendo ser, portanto, um ato dado de forma agressiva e desrespeitosa (CHEMIM, 2013).

Outro ponto importante a ser explorado, até mesmo para que os alunos compreendam que é necessário desconstruir o racismo internalizado, é que o racismo e o preconceito não nascem com as pessoas; elas adquirem esse sentimento conforme o tipo de aprendizagem que adquirem com os adultos, lembrando que o racismo é institucional e social, econômico e ético; e está presente em todas as esferas da sociedade moderna porque é um dos pilares históricos que a formula.

Outro ponto que pode ser explorado a partir da reflexão do conto em sala de aula é o conhecimento da Constituição da República Federativa do Brasil de 1988 (CRFB/88), 
artigo $5^{\circ}$ parágrafo XLII, que trata dos direitos e deveres individuais e coletivos inseridos no Título dos Direitos e Garantias Fundamentais, a prática de racismo é considerada um crime inafiançável e imprescritível, ou seja, não cabe fiança e nem prescreve, ademais pode ser dada a pena de reclusão conforme a lei (BRASIL, 1988).

Expandindo a reflexão do racismo para o ambiente acadêmico, com o intuito de conscientizar os alunos sobre a importância da representatividade e da ocupação de espaços até então negados a pessoas negras, é possível discutir, por exemplo, sobre a Lei de Cotas. Esta que é uma medida capaz de possibilitar a inclusão dos negros e das pessoas de baixa renda no meio acadêmico. Pode-se verificar que tais propósitos estão sendo adquiridos de forma a garantir representatividade.

Todavia, para que haja a efetividade da Lei, é necessário que as universidades federais adotem medidas para amparar os grupos vulneráveis ao acesso à universidade de forma igualitária (MARINHO; CARVALHO, 2018). Assim, além de gerar debates que buscam desconstruir o racismo estrutural, ainda é possível criar e expandir o horizonte dos alunos, mostrando que seus direitos devem ser garantidos.

Portanto, embasado nessas reflexões, compreende-se que o professor criará um ambiente capaz de possibilitar ao aluno compreender a dimensão da escravidão e o seu peso histórico. Trazendo para mais próximo do exemplo, o aluno poderá refletir, por exemplo, que foi por meio da Lei de Cotas que muitas pessoas negras tiveram a oportunidade de ingressar em universidade - que é uma instituição importantíssima para gerar mudanças sociais e diminuir a desigualdade socioeconômica.

Nas lendas, é possível constatar um rico campo de discussão a partir de seu uso como instrumento pedagógico. E, já no que diz respeito à ambientação deste gênero, além do preconceito racial, o ambiente também representa a religiosidade e o poder da Igreja Católica, na fala do padre, assim como é descrita a supremacia do homem branco. Podemos observar, por exemplo, que os personagens "o negro", "o padre" e "o branco" representam uma alegoria da formação da população brasileira: a força braçal do negro escravo, animalizado e objetificado, "caçado como fera", destituído de nome e "atirado ao porão infecto de um navio negreiro"; o poder da Igreja, "Seu legítimo representante na Terra”; e, apesar de não possuir discurso próprio na narrativa, o poder do homem branco é discutido através da fala reflexiva do negro: 
Quis denunciar-me quando o vi preso, acusado de desfalque, mas, pensei, ele é branco, será libertado um dia, eu, pobre escravo, então receberei em troca o chicote que me dilacerará as carnes até a morte. Doeu-me ver as injustiças que lhe fizeram e me pesa a consciência não ter confessado ser eu o ladrão (COUTO, 1954, p. 91).

Constatamos no discurso do negro moribundo, a construção de um discurso literário através de metáforas e paradoxos. Em "Chamei o padre para, neste ato final de minha vida, tirar-me um grilhão de consciência" o negro usa o termo grilhão como metáfora para referir-se à culpa que sente pelo fato de haver roubado e deixado outro responder por sua ação; logo após, ele trata sobre a escravidão dos homens, ocasionado pelo ouro e pelo diamante, "Apoderei-me do ouro e diamantes, mercadorias que escravizam os homens [...]”, escravidão sem distinção de raça: a escravidão da ambição do homem branco e a escravidão do homem negro, ocasionada pela ausência de liberdade.A conturbação de sentimentos do expirante vem à tona através de discursos paradoxais, em: "a pedra fascinante e o metal reluzente que serviram para aumentar minha desgraça" e "A diferença encontrada no cofre era o preço de minha liberdade". Fascinante e reluzente se contrapõem com o sentido de desgraça, enquanto cofre possui o sentido oposto de liberdade. Ambas as figuras de linguagem, paradoxo, antítese e metáfora, marcaram presença no período literário barroco, florescido com vigor em Diamantina e em outras localidades mineiras no século XVIII. Por fim, na morte, os protagonistas se desfazem do tesouro para retirar a marca de apropriadores de material alheio. O Negro entrega as coordenadas ao padre, a fim de ganhar o perdão divino, com um propósito nobre, para conseguir sua liberdade e retornar ao seu local de origem; o padre, por sua vez, deixa as coordenadas do tesouro alheio à sorte de quem o encontrar sem mencionar a quem pertence, demonstrando a insatisfação acerca da distribuição das riquezas naturais que estavam nas mãos da Coroa.

Logo, a presença das características que classificam esta narrativa como lenda: oralidade, persistência, anonimato e antiguidade. Aires da Mata Machado Filho, ao contar, no seu livro Noites e Dias em Diamantina, a lenda do Padre Brazão, ressalta: Conta a tradição antiga, segundo publicação na 'Estrela Polar' de 23/01/1972: “Sepultei ao pé de uma jabuticabeira" (MACHADO FILHO, 1972, p. 35), então, essa obra se originou da oralidade das pessoas que viveram em Diamantina. Perante isso, podemos afirmar que uma característica presente das lendas é a oralidade, a qual é construída de 
forma coletiva, e outra o anonimato, ou seja, ela não tem dono, pertence à coletividade de uma sociedade.

Outra característica das lendas é a antiguidade, dado que não se sabe a data correta que determinada lenda aconteceu, apenas que é uma história antiga, como foi falado acima. Ademais, a presença do personagem Felisberto Caldeira Brant nos situa, de forma mais ou menos precisa, no século que aconteceu a história. E, por fim, outra característica é a persistência, exemplo disso é nos depararmos com a reprodução dessa lenda publicada em blogs e sites, além de estar presente e viva na memória diamantinense. Ressaltamos que, apesar de apresentar personagens que fizeram parte da história, o texto é dado como ficção.

\section{CONSIDERAÇÕES FINAIS}

Esta pesquisa partiu das seguintes questões norteadoras: Como despertar o interesse pela leitura literária nos alunos? Como formar leitores literários? Como fazer com que os alunos compreendam o que leem? Essas são inquietações nos remetem ao tratamento do processo de ensino e aprendizagem escolar e seus objetivos educacionais, inclusive previstos nos documentos oficiais.

A escola é responsável por promover a formação leitora promovendo um processo de escolarização da literatura. Cabe a ela atuar "na formação de um leitor, não um leitor qualquer, mas um leitor crítico e participativo" (SOUZA; COSSON, 2011, p. 26). Mas, para que isso se realize, é necessário que as atividades em sala de aula favoreçam a aptidão do aluno para interpretar textos, possibilitando sua fruição e apropriação do texto literário para que ele possa se posicionar na sociedade. Oferecer uma educação de qualidade é uma demanda histórica que a sociedade brasileira ainda busca, pois as escolas têm tido dificuldades para garantir aprendizagens e conhecimentos essenciais para a formação de cidadãos autônomos, críticos e participativos (BRASIL, 1998). De acordo com Paulino e Cosson (2009), a escola precisa dar o suporte para que o aluno esteja preparado para colocar em prática a sua formação leitora em relação a outros textos literários com os quais terá contato em suas práticas sociais, dentro e fora da escola. É importante que o professor leve o aluno a reconhecer as narrativas ficcionais, pois elas trazem toda uma dimensão ética e estética “da atividade humana da linguagem” (BRASIL, 2014, p. 10).

Educação, Psicologia e Interfaces, Volume 4, Número 3, p.1-16, Julho/Setembro, 2020. 
A literatura oral traz em suas temáticas o sobrenatural, os mistérios e o desconhecido, o que pode instigar o leitor a querer saber o que acontece, ou o que aconteceu, ou o que aconteceria com um determinado personagem. Essas narrativas incitam a imaginação e podem ser uma prática motivadora para o desenvolvimento de habilidades de leitura, a compreensão e a produção textual. É necessário que a escola proporcione ao aluno a oportunidade de construir significados e tecer sua própria análise ao vivenciar as diversas formas de cultura presentes em um determinado contexto popular. Com esse propósito, propomos um material de apoio que contemple as análises dessas narrativas lendárias assim como propor atividades para trabalhar a literatura oral nas séries finais do ensino fundamental, pois esse tipo de literatura representa de forma marcante a cultura de uma determinada comunidade. Dentro da variedade de manifestações orais que se deve trabalhar com os alunos, destaca-se, no caso da nossa região, o gênero lenda, por meio do qual se possibilita o conhecimento de uma parte da diversidade cultural aqui presente.

\section{REFERÊNCIAS BIBLIOGRÁFICAS}

BRASIL. [Constituição (1988)]. Constituição da República Federativa do Brasil de 1988. Brasília, DF: Presidência da República, 1988. Disponível em: http://www.planalto.gov.br/ccivil_03/Constituicao/Constituiçao.htm. Acesso em: 24 set. 2018.

BRASIL. Lei no 13.005, de 25 de junho de 2014. Aprova o Plano Nacional de Educação - PNE e dá outras providências. Brasília, 2014. Disponível em: http://www.planalto.gov.br/ccivil_03/_ato2011-2014/2014/lei/113005.htm. Acesso em: 24 set. 2018.

CHEMIM, M. S. A. Os desafios da escola pública paranaense na perspectiva do professor PDE. 2013. In: Caderno pedagógico. O negro no espaço escolar. v. 1, p. 119, 2013.

CHIZZOTTI, A. Pesquisa em Ciências Humanas e Sociais. 4 ed. São Paulo: Cortez, 2000.

COSSON, R. Letramento literário: teoria e Prática. São Paulo: Contexto, 2009.

SOUZA, R. J.; COSSON, R. Letramento literário: uma proposta para a sala de aula. Caderno de Formação: formação de professores, didática de conteúdos. São Paulo:

Cultura Acadêmica, v. 2, p. 101-107, 2011.

COUTO, S. Vultos e fatos de Diamantina. 1. ed. Belo Horizonte: Impr. Oficial, 1954. 
GANCHO, C. V. Como Analisar Narrativas. 7. ed. São Paulo: Ática, 1991.

GIL, A. C. Como elaborar projetos de pesquisa. 3. ed. São Paulo: Atlas, 1991.

MACHADO FILHO, A. M. Dias e noites em Diamantina. Belo Horizonte: Maciel, 1972.

MARINHO, A. C.; CARVALHO, M. H. P. Ações afirmativas e o princípio da igualdade: cotas raciais, um instrumento social para a promoção da igualdade de oportunidades. Revista Ceuma Perspectivas, v. 31, n. 1, p. 34-48, Jan/Jul, 2018. Disponível em: http://www.ceuma.br/portalderevistas/index.php/RCCP/article/view/177 Acesso em: 10 jan. 2019.

PAULINO, G.; COSSON, R. Letramento Literário: para viver a Literatura dentro e fora da escola. In: ZILBERMAN, R.; RÖSING, T. M. K. Escola e leitura: velha crise, novas alternativas. São Paulo: Editora Global, 2009.

SANTOS, J. F. Memórias do Distrito Diamantino. 4. ed. São Paulo: Editora Itatiaia, 1976.

SEVERINO, A. J. Metodologia do trabalho científico. 23. ed. São Paulo: Cortez, 2007.

TORRES, J. C. O. História de Minas Gerais. 3. ed. Belo Horizonte: Lemi; 1980.

\section{Credenciais da/os autora/es}

TEIXEIRA, Daniela Luciana Braga Santiago. Técnica administrativa na Universidade Federal dos Vales do Jequitinhonha e Mucuri (UFVJM), graduada em Letras licenciatura - (FAFIDIA), Mestranda em Educação Profissional (UFVJM). (D) Orcid: https://orcid.org/0000-0003-1205-5386. E-mail: daniela.teixeira@ufvjm.edu.br

Endereço para correspondência: Daniela Luciana Braga Santiago Teixeira. Avenida Padre Caio, n. 76, Bairro Arraiolos, CEP: 39100-000, Diamantina/MG. E-mail: daniela.teixeira@ufvjm.edu.br

Como citar este artigo (Formato ABNT): TEIXEIRA, Daniela Luciana Braga Santiago. Literatura Oral, Lendas Diamantinenses e Formação Leitora. Educação, Psicologia e Interfaces, v. 4, n.3, p. 1-16, 2020. Doi:10.37444/issn-2594-5343.v4i3.250

Recebido:27/02/2020.

Aceito: 04/05/2020. 